\title{
Controlled meteorological (CMET) free balloon profiling of the Arctic atmospheric boundary layer around Spitsbergen compared to ERA-Interim and Arctic System Reanalyses
}

\author{
Tjarda J. Roberts ${ }^{1,2}$, Marina Dütsch ${ }^{3,4}$, Lars R. Hole ${ }^{3}$, and Paul B. Voss ${ }^{5}$ \\ ${ }^{1}$ LPC2E/CNRS, 3A, Avenue de la Recherche Scientifique, 45071 Orléans, CEDEX 2, France \\ ${ }^{2}$ Norwegian Polar Institute, Fram Centre, 9296 Troms $\varnothing$, Norway \\ ${ }^{3}$ Norwegian Meteorological Institute, Bergen, Norway \\ ${ }^{4}$ Institute for Atmospheric and Climate Science, ETH Zurich, 8092 Zurich, Switzerland \\ ${ }^{5}$ Smith College, Picker Engineering Program, Northampton, MA, USA
}

Correspondence to: Tjarda J. Roberts (tjardaroberts@gmail.com)

Received: 22 May 2015 - Published in Atmos. Chem. Phys. Discuss.: 14 October 2015

Revised: 4 July 2016 - Accepted: 18 July 2016 - Published: 30 September 2016

\begin{abstract}
Observations from CMET (Controlled Meteorological) balloons are analysed to provide insights into tropospheric meteorological conditions (temperature, humidity, wind) around Svalbard, European High Arctic. Five Controlled Meteorological (CMET) balloons were launched from Ny-Ålesund in Svalbard (Spitsbergen) over 5-12 May 2011 and measured vertical atmospheric profiles over coastal areas to both the east and west. One notable CMET flight achieved a suite of 18 continuous soundings that probed the Arctic marine boundary layer (ABL) over a period of more than $10 \mathrm{~h}$. Profiles from two CMET flights are compared to model output from ECMWF Era-Interim reanalysis (ERA-I) and to a high-resolution $(15 \mathrm{~km})$ Arctic System Reanalysis (ASR) product. To the east of Svalbard over sea ice, the CMET observed a stable ABL profile with a temperature inversion that was reproduced by ASR but not captured by ERA-I. In a coastal ice-free region to the west of Svalbard, the CMET observed a stable ABL with strong wind shear. The CMET profiles document increases in ABL temperature and humidity that are broadly reproduced by both ASR and ERA-I. The ASR finds a more stably stratified ABL than observed but captured the wind shear in contrast to ERAI. Detailed analysis of the coastal CMET-automated soundings identifies small-scale temperature and humidity variations with a low-level flow and provides an estimate of local wind fields. We demonstrate that CMET balloons are a valuable approach for profiling the free atmosphere and boundary
\end{abstract}

layer in remote regions such as the Arctic, where few other in situ observations are available for model validation.

\section{Introduction}

In remote regions such as the Arctic there exists very limited in situ observational data to evaluate atmospheric models. This study demonstrates CMET (Controlled Meteorological) balloons as a new approach for detailed probing of the Arctic atmospheric boundary layer on local-to-regional scales and compares the observations to model reanalysis outputs.

Accurate representation of polar meteorology and smallscale air-sea ice interaction processes is essential for meteorological forecast models and to understand climate in the Arctic, a region undergoing rapid change (Vihma et al., 2014). The atmospheric boundary layer in the Arctic is usually strongly stable during winter and only weakly stable to neutral during summer (Persson et al., 2002). Strong temperature inversions can occur as warmer air masses from lower latitudes are advected over the cold polar air masses. This stability acts as a barrier to vertical atmospheric mixing and exchange and can magnify flows over small-scale topography such as channelling and katabatic flows. The Barents Sea near Svalbard is especially implicated in Arctic climate (Smedsrud et al., 2013). To the east of Svalbard, the Barents Sea is typically partially covered by sea ice during winter and 
spring, whilst sea ice is typically absent in the Greenland Sea to the west of Svalbard. This is due to the northward flowing warm and saline Atlantic Warm Current (AWC) or North Atlantic Drift, which elevates temperatures along Svalbard's west coast, with a secondary branch that enters the Barents Sea. The warm saline AWC releases heat to the atmosphere as it cools to sink beneath the polar waters. The polar waters experience thermodynamic formation, growth and melt of sea ice as well as wind- and oceanic-current-driven advection of sea ice, which can lead to highly variable surface conditions that affect air-sea exchange of heat and momentum and the radiative balance, e.g. through albedo. Even at high sea ice density, small patches of open water amongst very close (90-100\%) or close (80-90\%) drift ice tend to promote sea-air exchange, enhancing both temperature and specific humidity at the surface (Andreas et al., 2002). Conversely, snow deposited upon sea ice provides an insulating layer that reduces heat exchange. Hence, heat and energy fluxes to the Arctic atmospheric boundary layer can vary by several orders of magnitude, depending on the surface state (Kilpeläinen et al., 2011).

Model reanalyses provide temporally consistent representations of atmospheric and surface state and are a valuable tool for understanding Arctic processes and climate. A global model reanalysis product is ERA-Interim (ERA-I) from the European Centre for Medium-Range Weather Forecasts (ECMWF), Dee et al. (2011). At approximately $80 \mathrm{~km}$ resolution, ERA-I has been widely used including for Arctic studies, e.g. Rinke et al. (2006). Recently, Arctic System Reanalysis (ASR) products have been developed at higher resolution $(15-30 \mathrm{~km})$ and specifically focused on high latitudes (Bromwich et al., 2016). There is an ongoing effort to validate and compare the ASR and ERA-I reanalyses data sets. The ASR (version 1: $30 \mathrm{~km}$ resolution) and ERA-I reanalyses exhibit comparable RMS errors for surface meteorology compared to Arctic-wide collated meteorological station data (December 2006-November 2007), (Bromwich et al., 2016). Wind speed biases were significantly smaller in the ASRv1. North of $60^{\circ} \mathrm{N}$, ASRv1 showed smaller precipitation biases than ERA-I except during summer. Moore et al. (2015) showed that the higher-resolution ASRv1 is more able to fully resolve mesoscale features in the atmosphere, such as katabatic wind, to the south-east of Greenland, compared to ERA-I. Wesslén et al. (2014) compared ASRv1 and ERA-I reanalyses to surface and radiosonde meteorological data obtained during a 3-week ice drift experiment in summer 2008, a period typically influenced by clouds. ERA-I was found to have a systematic warm bias in the lowest troposphere, whilst ASRv1 had a systematic cold bias of similar magnitude. The ASR version 2 at $15 \mathrm{~km}$ resolution has recently been developed. Moore et al. (2016) demonstrate the added value of ASRv2 compared to ASRv1 in resolving topographically forced winds and capturing mesoscale spatial features around Greenland due to the higher resolution.
In this study we compare ASRv2 (at $15 \mathrm{~km}$ resolution) and ERA-I to in situ CMET balloon observations in the Svalbard region during the 2011 Arctic spring. In this region in situ measurements of the boundary layer and lower troposphere are limited. Meteorological stations provide continuous ground-based data and regular daily meteorological balloon profiles, but are sparsely located. In Svalbard, such data sets may be occasionally supplemented by tethered balloon or meteorological mast observations (e.g. Mäkiranta et al., 2011). Intensive field campaigns probe more remote regions of the Arctic by aircraft (e.g. Vihma et al., 2005) or by drifting ice stations (e.g. Rinke et al., 2006, Tjernström et al., 2012), but these can only be rarely undertaken due to cost. Remotely piloted aircraft systems (RPAS) also known as unmanned aerial vehicles (UAV) equipped with meteorological sensors provide an alternative cost-effective means to spatially probe the Arctic boundary layer around Svalbard at local scales, Mayer et al. (2012a, b). However, most UAVs are operated over timescales up to a few hours and over ranges typically limited to a few $10 \mathrm{~s}$ of $\mathrm{km}$. For low-altitude flights the range may be further limited if terrain blocks the signal.

To provide an in situ meteorological data set that samples the wider Svalbard Arctic region we deployed five Controlled Meteorological (CMET) balloons, launched in May 2011 from Ny-Ålesund in Svalbard. CMET balloons are capable of performing sustained flights within the troposphere at designated altitudes and can make vertical soundings at any time during the balloon flight on command via satellite link (Voss et al., 2012). The nested dual balloon design ensures very little helium loss, enabling the balloons to make multi-day flights. This gives an opportunity to investigate areas far away from research bases, at greater spatial scales (many hundreds of kilometres from the launch point) than can be obtained by line-of-sight RPAS/UAV approaches, radiosondes or tethered balloons. The study builds upon previous uses of CMET balloons to probe regional-scale meteorology including atmospheric trajectories (Riddle et al., 2006), air flow downwind from a city pollution source (Voss et al., 2010) and Antarctic meteorology on local-to-regional scales (Stenmark et al., 2014; Hole et al., 2016). Here we demonstrate the capability of CMET balloons to repeatedly make in-flight soundings down to low altitudes that reach into the atmospheric boundary layer. We present multiple CMET flights of long duration (up to several days) in the Arctic including a CMET configured to make automated continuous profiling into the atmospheric boundary layer. These CMET in situ profiles of temperature, humidity and wind are compared to ERA-I and ASR model reanalyses. 


\section{Methods}

\subsection{CMET balloon and payload description}

Controlled Meteorological (CMET) balloons can fly for multiple days in the troposphere with altitude controlled via satellite link (Voss et al., 2012). Altitude control is achieved by the dual balloon design (high-pressure inner and lowpressure outer balloon) between which helium is transferred by a miniature pump-valve system. Commands sent through an Iridium satellite link can set target altitude (typically 0 $3500 \mathrm{~m})$, control band $(\sim 50-500 \mathrm{~m}$ with the higher band using less power), vertical velocity $\left(\sim 0.5-1.5 \mathrm{~m} \mathrm{~s}^{-1}\right)$, termination countdown timer and numerous other operational parameters. For this study, a new capacity was added to perform automated soundings between two specified pressure altitudes.

The $215 \mathrm{~g}$ CMET payload (excluding balloon envelopes) includes the control electronics, GPS receiver, satellite modem, pump-valve system, lithium polymer battery, photovoltaic panel, aspirated T-RH sensor and a vacuum-insulated pouch for the payload. The payload temperature is maintained within acceptable operating limits (typically $+20^{\circ} \mathrm{C}$ above ambient) even at altitudes of several kilometres in the Arctic.

An aviation-grade pressure sensor (Freescale MPXH6115A) coupled to a 16 bit analog-to-digital converter (Analog Devices AD7795) provides altitude information to the balloon's control algorithm every $10 \mathrm{~s}$ during flight. As part of data post-processing, this pressurederived altitude is corrected for pressure offsets using the in-flight GPS altitude (Inventek ISM300X). GPS latitude and longitude provide the in-flight CMET coordinates and are also further analysed during flight to determine wind speeds in eastward $(U)$ and northward $(V)$ directions.

Temperature is measured using a thermistor (General Electric MC65F103A) in a 10 k-Ohm divider circuit coupled to the aforementioned analog-to-digital converter. A capacitance humidity sensor (G-TUCN.34 from UPSI, covering 2 to $98 \% \mathrm{RH}$ range over -40 to $+85^{\circ} \mathrm{C}$ ) generates a signal which is a function of the ambient relative humidity $(\mathrm{RH})$ with respect to water. Relative humidity was converted to specific humidity $(Q)$ for comparison to the ERA-I and ASR model outputs.

CMETs are relatively simple to launch (requiring just 1-2 people with standard meteorological balloon skills: launches have been achieved under a wide range of surface winds to date) and are similar in size to a standard meteorological balloon. Further details of the CMET balloon, payload design and balloon flight engineering are described by Voss et al. (2012) and illustrated at http://www.science.smith.edu/ cmet/flight.html.
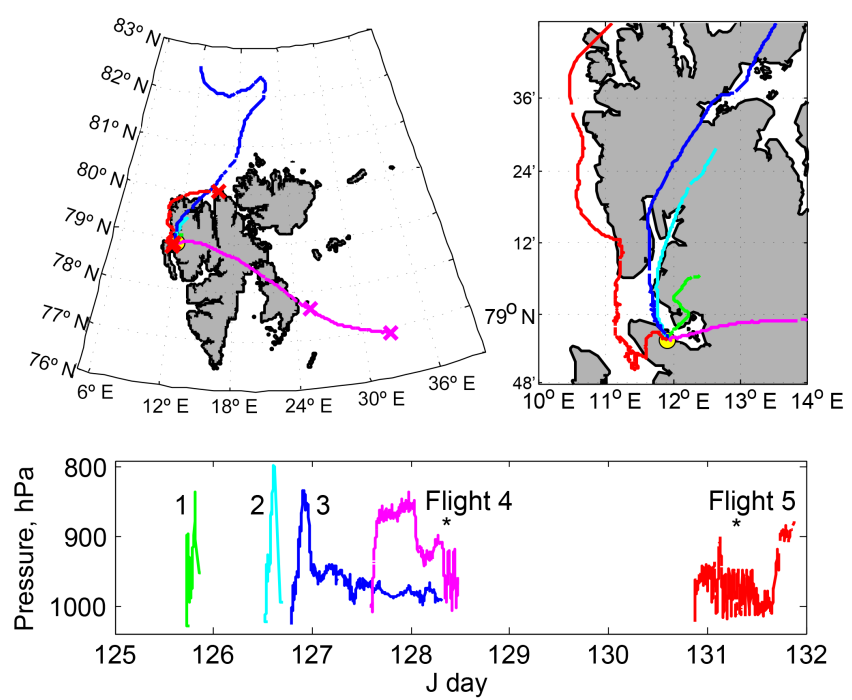

Figure 1. Trajectories of five CMET balloons launched from $\mathrm{Ny}$ Ålesund in May 2011. Flight paths are shown on the regional scale of the island Spitsbergen, Svalbard and on the local scale of Kongsfjord. Ny Ålesund is marked by a yellow circle and lies at the southern side of Kongsfjord. Balloons 4 and 5 performed repeated soundings as shown by the pressure variations in time (marked*). Analysis periods for flights 4 (06:00-12:00 UTC) and 5 (full flight) are denoted by $\mathrm{x}$.

\subsection{Balloon launches in Svalbard}

Five CMET balloons were launched from the research station of the Alfred Wegener Institute and the Polar Institute Paul Emile Victor (AWIPEV) in Ny Ålesund, over the period 5 to 12 May 2011 (JD 125 to 132) (Fig. 1). Balloons 1 and 2 had short flights due to technical issues encountered at the start of the campaign. Balloon 3 flew far north and was the longest duration flight in this campaign but did not perform any soundings after leaving the coastal area of Svalbard. Balloon 4 flew eastwards, but despite good balloon performance needed to be terminated before encroaching Russian airspace. It performed two closely spaced (ascent and descent) soundings over sea ice in the Barents Sea, east of Svalbard. Balloon 5 undertook a $24 \mathrm{~h}$ duration flight that first exited Kongsfjorden, then flew northwards along the coast. It was placed into an automated sounding mode and achieved a much longer series of 18 consecutive profiles of the $\mathrm{ABL}$, before being raised to higher altitudes where winds advected it eastwards. To the best of our knowledge, this was the first demonstration of a set of extended controlled soundings made using a free balloon.

The data analysis of this study focuses on balloon flights 4 and 5, which made repeated soundings quantifying the following meteorological variables as a function of pressure (altitude): temperature $(T)$, specific humidity $(Q)$ and northward and eastward winds $(V, U)$. The balloon locations during these flights are shown in Fig. 1. A detailed model 

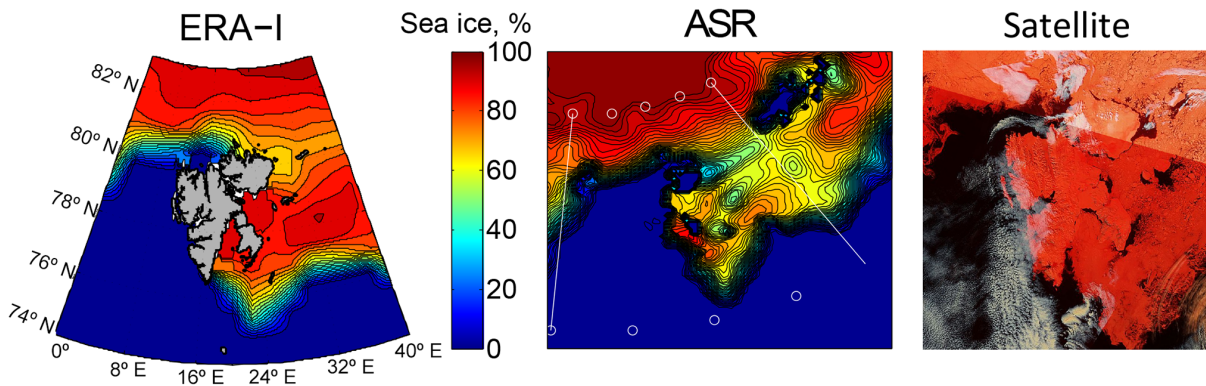

Figure 2. Sea ice concentration field on 8 May (JD 128) in ERA-I and ASR reanalyses. The ERA-I image shows a map of Svalbard overlain. The ERA-I map coordinates are depicted on the ASR image for ease of comparison. Also shown is the Lance rapid response image (right) from the MODIS satellite (downloaded from http://lance-modis.eosdis.nasa.gov/, land and sea ice are shown in red, cloud cover in white) for 5 May 2011 (JD 125).

comparison is made for flight 4 over time periods 06:0012:00 UTC on 8 May (JD 128) and for the $24 \mathrm{~h}$ flight 5 (21:00-21:00 UTC) on 10-11 May (JD 130-131).

\subsection{Model reanalyses products ERA-I and ASR}

The CMET observations are compared to two model reanalyses: ECMWF ERA-Interim (Dee et al., 2011) and the Arctic System Reanalysis (Bromwich et al., 2016). ERAI (available from http://apps.ecmwf.int/) has approximately $80 \mathrm{~km}$ (T255 spectral) resolution on 60 vertical model levels from the surface up to $0.1 \mathrm{hPa}$, at 6-hourly resolution. The boundary layer and lower troposphere $(>\sim 800 \mathrm{hPa})$ correspond to 14 model levels. For this study, bilinearly interpolated model level data were downloaded at $0.125^{\circ}$ spatial resolution, then further linearly interpolated. ASR uses the polar-optimized version of the Weather Research and Forecasting Model (Polar-WRF: Bromwich et al., 2009) with an inner domain that extends over latitudes $>40^{\circ} \mathrm{N}$, using ERA-I output as boundary conditions. ASR (version 2) has $15 \mathrm{~km}$ resolution on 70 vertical model levels from the surface up to $0.1 \mathrm{hPa}$, at 3-hourly resolution (ASR version 1 at $30 \mathrm{~km}$ resolution is used in this study only for comparison to a surface station). The boundary layer and lower troposphere $(>\sim 800 \mathrm{hPa}$ ) correspond to 30 model levels. For this study, full ASRv2 model level data were made specially available by the ASR team for selected field dates. Pressurelevel data for ASRv2 will soon be publicly available from http://rda.ucar.edu/. The ASR and ERA-I reanalyses were 4$\mathrm{D}$ (latitude, longitude, pressure and time) interpolated to the CMET balloon for direct comparison. A main difference between these two reanalyses is the much higher temporal (3hourly) and spatial $(15 \mathrm{~km})$ resolution of ASR. This provides a more highly resolved simulation of small-scale meteorological processes (especially within the boundary layer) as well as topography. Another difference is that ASR Polar WRF has non-hydrostatic dynamics whilst ERA-I pressure is hydrostatic. Both model reanalyses include assimilation of remotely sensed retrievals and in situ surface and upper air data, 4-D for ERA-I and 3-D for ASR. ASR uses a highresolution land data assimilation system and uses Polar WRF which includes the Noah land surface model and a detailed fractional sea ice description including extent, concentration, thickness, albedo and snow cover (see Bromwich et al., 2016 for details). For ERA-I surface properties are less detailed (spatio-temporally) than for ASR, but sea ice is also fractional and updated daily.

Sea ice concentration in ERA-I and ASR models is shown in Fig. 2 for 8 May (JD 128), the date of the CMET flight 4 soundings. Also shown is a satellite image of sea ice coverage (obtained for 5 May, JD 125). The west of Svalbard is ice-free, consistent with sea-surface temperature in this region (see Introduction), whilst dense sea ice occurs east of Svalbard. The satellite image also shows some small-scale features in ice-free areas (polynyas). These are not seen in the ERA-I ice-field but are represented in ASR as zones of lower ice concentration.

\section{Results and discussion}

\subsection{Meteorological conditions during the campaign}

The period of 5-12 May 2011 was characterized by rapidly changing meteorological conditions, reflected in the different CMET flight paths (Fig. 1). The time evolution of the pressure systems driving the winds that advected the CMETs is illustrated by ERA-I model surface pressure maps in Fig. 3 . The start of the campaign is influenced by a high-pressure system that slowly advected balloon 3 northwards. A lowpressure system then developed to the north and east of Svalbard, which is responsible for the south-eastwards advection of balloon 4. Presence of a high-pressure system causes a slow northwards, followed by an eastwards advection of balloon 5. Surface observations (resolution in minutes) from the AWIPEV meteorological station in Ny-Ålesund (Maturilli et al., 2013) are shown alongside the ERA-I and ASR model outputs in Fig. 4. The greatest wind speeds during the cam- 

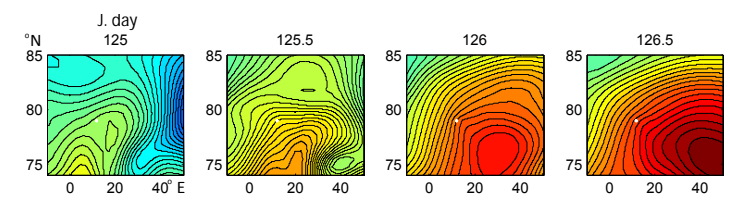

127

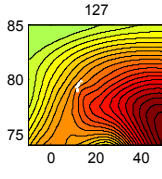

127.5

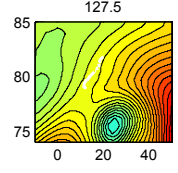

128

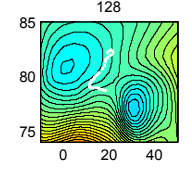

128.5

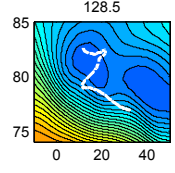

129.5
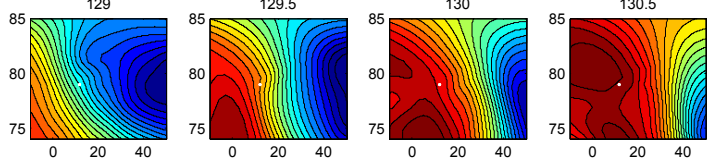

132
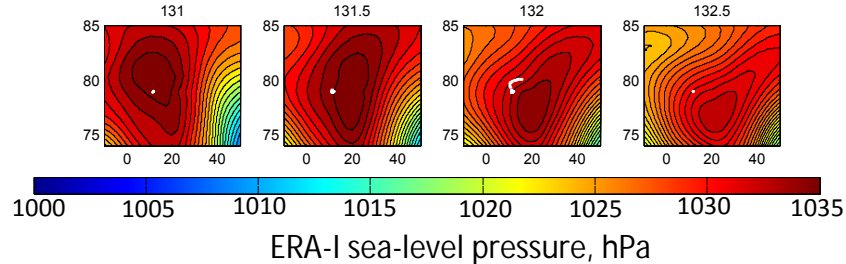

Figure 3. Sea-level pressure in ERA-I shown as a function of latitude and longitude at 12-hourly intervals for the duration of the field campaign, starting on JD 125 (5 May). Overlain in white are $\mathrm{Ny}-\AA$ Alesund and the CMET flight tracks as a function in time (full extents of flights 3 and 4 are shown at JD 128.5 and for flight 5 at JD 132).

paign are observed on 8-10 May with the AVIPEV station registering a maximum wind speed of $17.4 \mathrm{~m} \mathrm{~s}^{-1}$ around noon on 9 May. During this period the winds became northwesterly due to the presence of a high-pressure system SW and a lower-pressure system NE of Svalbard. This caused temperature to decrease during this period. This was followed by a period of low wind speed over 11-12 May, also reflected in the $24 \mathrm{~h}$ CMET flight to the east of Svalbard, with low but increasing temperatures recorded at the meteorological station. Both models show good general agreement with the Ny-Ålesund surface meteorological observations of $2 \mathrm{~m}$ temperature, relative humidity and surface pressure (Fig. 4). This is not entirely unexpected given the use of data assimilation in both reanalyses. The models reproduced the variation in $10 \mathrm{~m}$ wind speed, but not always the wind direction reported at AWI-PEV (Fig. 4). This is likely due to known along-fjord wind channelling in the Kongsfjorden that occurs on finer scales than the resolution of the reanalyses. Indeed, Esau and Repina (2012) found that even a very fineresolution model $(56 \times 61 \mathrm{~m}$ grid cell $)$ could not fully resolve near-surface small-scale turbulence in the strongly stratified Kongsfjorden atmosphere, where the valley is surrounded by steep mountain topography.
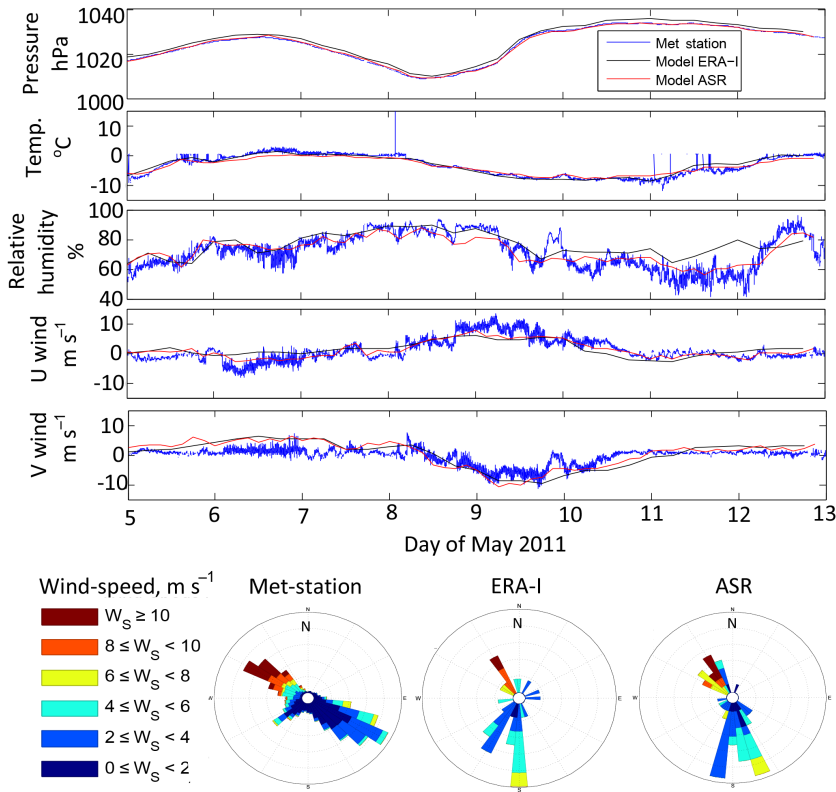

Figure 4. Meteorology parameter time series (resolution in minutes) from the Ny-Ålesund AWIPEV station compared to ERA-I (6-hourly) and ASR (3-hourly) outputs for pressure, temperature, relative humidity, $U$ and $V$ winds. Wind roses compare modelled and observed wind directions.

\subsection{CMET profiles over sea ice compared to ERA-I and ASR: temperature inversion}

The two consecutive CMET profiles of temperature, specific humidity, $U$ and $V$ winds over sea ice east of Svalbard (balloon flight 4) on the morning of JD 128 are compared to 4-D interpolated ERA-I and ASR model data (Figs. 5 and 6). The in-flight CMET soundings quantify temperature and humidity profiles which increase towards the surface as expected, as well as winds (derived from the balloon flight path) from the north-west. There is good general agreement with ASR and ERA-I. However, the CMET observes a temperature inversion at around 990-970 $\mathrm{hPa}$ which persists for most of the sounding time series. This temperature inversion is captured by ASR in good agreement with the CMET but is not reproduced by ERA-I. ASR finds a strong gradient in humidity related to this inversion barrier, but the CMET observes a more shallow humidity gradient. ERA-I finds an even shallower gradient in humidity than the CMET. Both models show strengthening westerly winds during the soundings, as observed. The CMET observed a reversal in $V$ winds near the surface $(>1000 \mathrm{hPa})$. This is better captured by ASR than ERA-I, where it is related in the model to the inversion layer. However, there are differences in $V$ winds at higher altitudes, which are more variable in ASR than in the CMET and ERAI.

The potential temperature and specific humidity profiles from the CMET flight are further shown in Fig. 7, alongside 

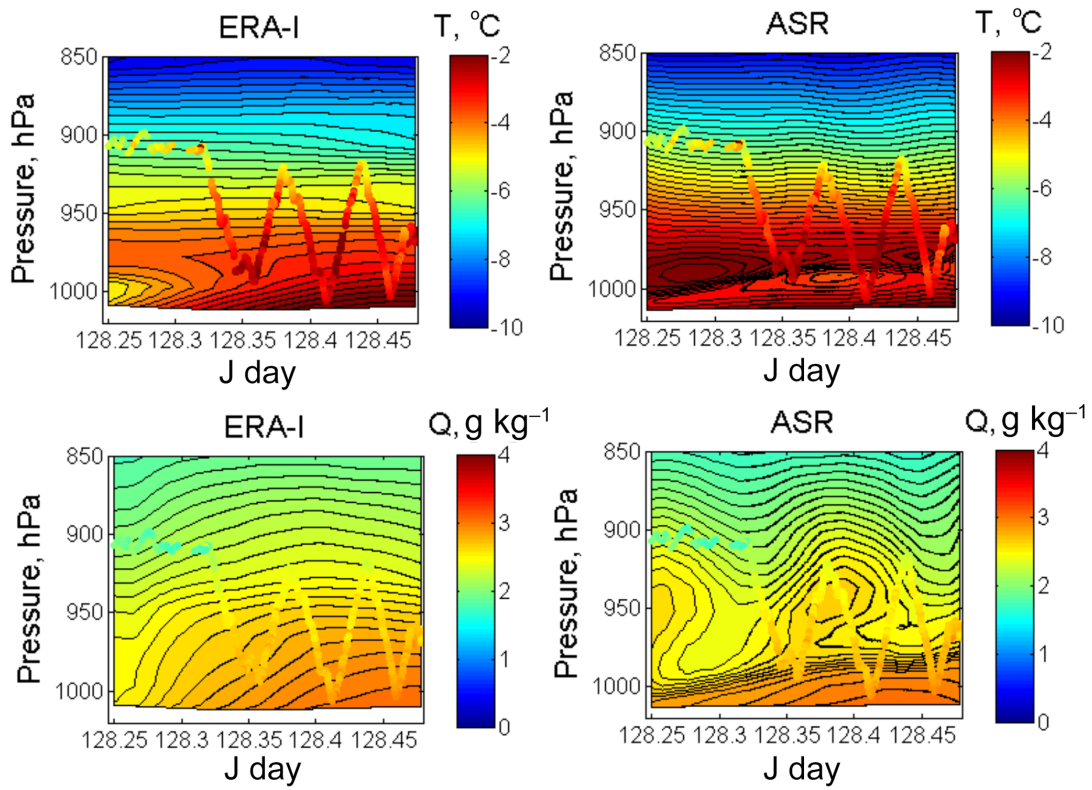

Figure 5. Temperature and specific humidity measured during the CMET flight 4 soundings (filled circles) compared to 4-D interpolated (latitude, longitude, pressure, time) model data from ERA-I and ASR.
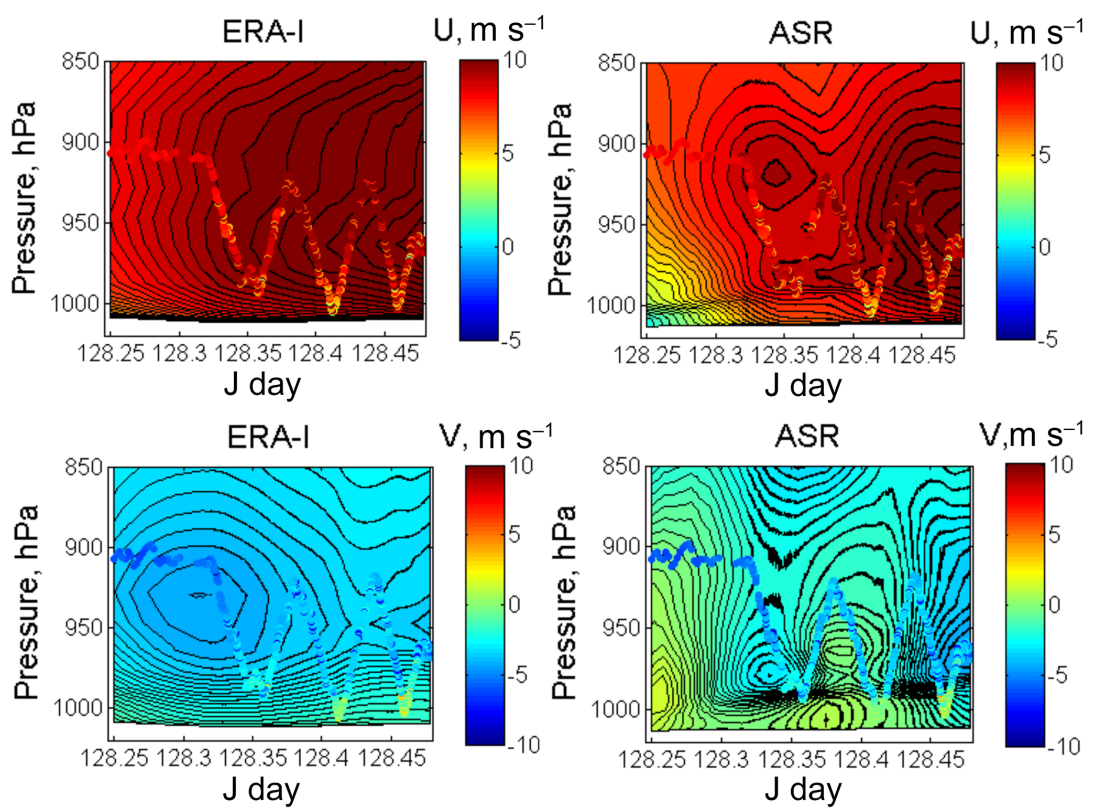

Figure 6. $U$ and $V$ winds observed during the CMET flight 4 soundings (filled circles) compared to 4-D interpolated (latitude, longitude, pressure, time) model data from ERA-I and ASR.

equivalent 4-D interpolated model outputs at each CMET latitude, longitude, pressure and time location. The CMET potential temperature profile shows two distinct layers: a strongly stable layer between 990 and $970-980 \mathrm{hPa}$ (related to the abovementioned inversion) and a stable layer $<980 \mathrm{hPa}$. This agrees well with similar layers identified in the ASR, whereas the absence of an inversion layer in ERA-I leads to a more linear potential temperature profile.
The specific humidity profile of ASR shows better agreement with CMET at $\sim 980 \mathrm{hPa}$, whereas ERA-I overestimates it by $0.2 \mathrm{~g} \mathrm{~kg}^{-1}$. At higher altitudes, ERA-I is in better agreement whilst ASR shows greater humidity variability (overestimations by up to $0.3 \mathrm{~g} \mathrm{~kg}^{-1}$ ) than the trend observed by CMET.

It is difficult to infer any temporal trend in the flight 4 CMET profiles over the morning of JD 128. The final profile (JD > 128.45) shows slightly greater humidity at low al- 

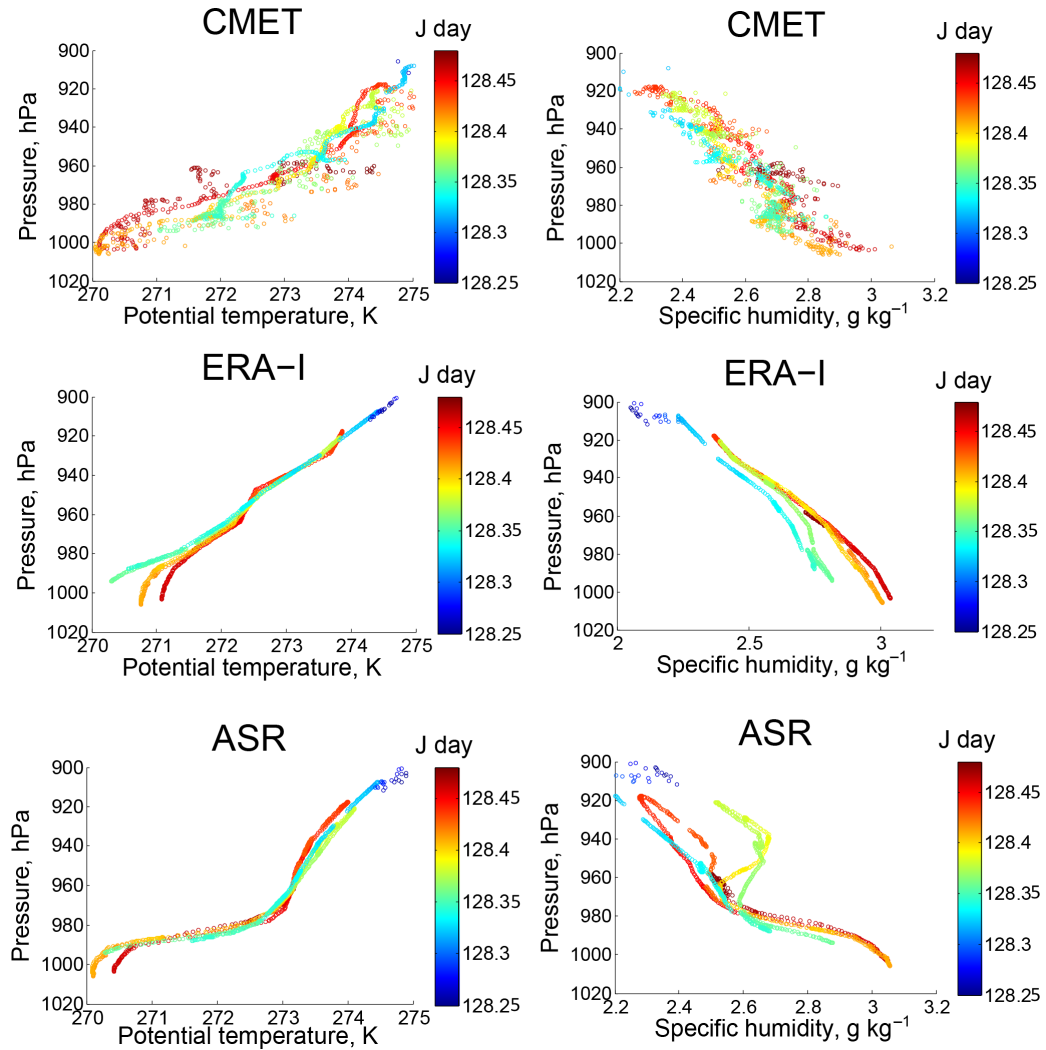

Figure 7. Profiles of potential temperature and specific humidity during flight 4 as observed by the CMET balloon and according to the 4-D interpolated ERA-I and ASR model outputs.

titudes but also slightly lower temperature and the inversion is less clear. ERA-I and ASR show a tendency for increasing surface temperature and humidity. In the morning ASR predicts a deepening layer beneath the inversion, but the top remains at constant height. Unfortunately the experiment could not be continued eastwards into the afternoon as the CMET flight had to be terminated to avoid Russian airspace.

\subsection{CMET profiles in coastal area compared to ERA-I and ASR: wind shear and temperature and humidity trends}

Flight 5 provided a series of 18 boundary layer profiles over a sea-ice-free region west of Svalbard. With the low wind speeds $\left(<5 \mathrm{~m} \mathrm{~s}^{-1}\right)$, the $24 \mathrm{~h}$ balloon trajectory remained relatively close to the Svalbard coastline. Figures 8 and 9 compare the along-flight profiles of temperature, specific humidity and $U$ and $V$ winds measured by the CMET to ERA-I and ASR model reanalyses. From morning to afternoon increases in temperature and humidity at the surface are observed by the CMET and shown by both models. Note that the lowest ERA-I model level intersects the CMET sounding at low altitudes (likely due to non-realistic surface topography), preventing model comparison, whereas this problem does not occur for ASR.
Overall there is good agreement between the reanalyses and CMET observations but some differences remain. During the night of JD 130-131, ERA-I underestimates temperature compared to CMET. This is better reproduced by ASR up until midday on JD 131, although still underpredicted. Both models and the CMET nevertheless show relatively small variations in the temperature profiles at this time. Humidity is well reproduced by ASR during the JD 130-131 night and only slightly underestimated by ERA-I. On the morning of JD 131, ERA-I reproduces the observed enhanced humidity near the surface better than ASR. In ASR the vertical humidity transition is sharper than observed by the CMET and humidity is underestimated near the surface. Both ERA-I and ASR capture the observed increase in nearsurface temperature and specific humidity up to the midafternoon. However, the CMET temperature increase is either stronger or earlier than in the models. These temperature and humidity enhancements are also spatio-temporally more localized for ASR than ERA-I. This leads to closer CMET agreement with ERA-I for mid-afternoon temperature but with ASR for humidity. Temperature is underestimated by both models at high altitudes in the evening of JD 131 whilst humidity is well reproduced (slightly overestimated by ERAI). 

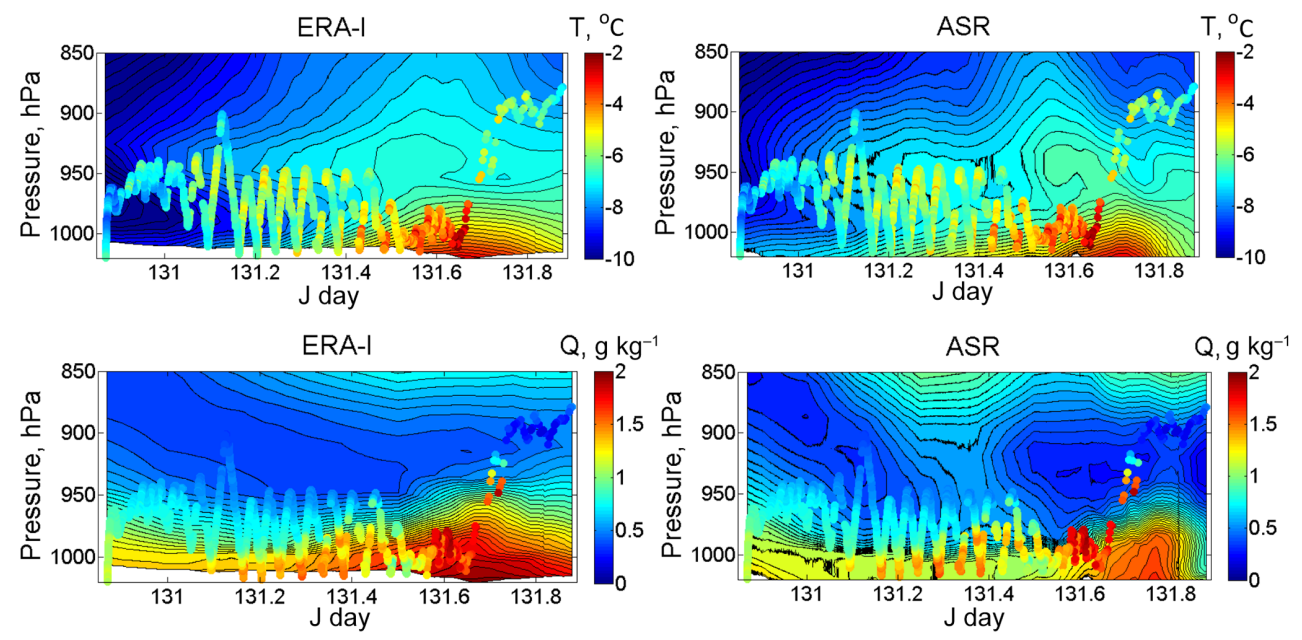

Figure 8. Temperature and specific humidity measured during the CMET flight 5 soundings (filled circles) compared to 4-D interpolated (latitude, longitude, pressure, time) model data from ERA-I and ASR.

There are also differences in the $U$ and $V$ winds between ASR and ERA-I (Fig. 9). The CMET observes strong $V$ wind shear on the morning of JD 131. This wind shear pattern is reproduced by ASR but is not captured by ERA-I. $V$ winds become southerly (from direction) in mid-afternoon in both models, but are more localized in ASR, leading to better early afternoon model agreement, although ERA-I better reproduces the persistence of southerly $V$ winds to higher altitudes observed during the afternoon on JD 131 . Westerly $U$ winds are modelled and observed on the evening of JD 131. ERA-I shows high positive $U$ winds at high altitudes only, whereas ASR shows high positive $U$ winds at almost all levels.

Closer inspection of the CMET temperature shows some signs of hysteresis in this flight with greater temperatures reached during ascents than descents. This is despite the fast time response of the (aspirated) thermistor. A possible explanation might be the heating of the balloon surface by the sun, raising the temperature of the air layer in direct contact with the balloon. This air layer could be transported over the sensor during ascent, but not descent profiles. Nevertheless, measurements made during descent only $\left(>0.1 \mathrm{~m} \mathrm{~s}^{-1}\right.$ vertical descent speed) are consistent with the complete ascentdescent in potential temperature and specific humidity profiles (Fig. 10). These profiles show an overall increase ( $\sim 5-$ $6 \mathrm{~K})$ in potential temperature observed close to the surface, which is reproduced by the models except for where ASR underpredicts the temperature rise $(\sim 3-4 \mathrm{~K})$ and ERA-I exhibits a potential temperature bias of $\sim-2 \mathrm{~K}$. The observed trend in surface specific humidity is less clear but with an overall enhancement. ASR specific humidity is in agreement with the CMET on JD 131 morning but is underestimated by up to $0.5 \mathrm{~g} \mathrm{~kg}^{-1}$ during the afternoon. ERA-I better captures the afternoon humidity maximum (and in early morning) but overestimates midday humidity by $0.5 \mathrm{~g} \mathrm{~kg}^{-1}$. The CMET and model flight 5 profiles show less stable conditions than found for flight 4 (which showed an inversion layer).

\subsection{CMET soundings in detail: decoupled flows and wind field estimation}

Further analysis of the observations from the CMET flight 5 on JD 131 enables consideration of local-scale patterns at higher resolution than the reanalyses. The observed profiles of potential temperature, specific humidity, wind speed and wind direction over $\sim 02-12.5$ UTC (JD 131.08-131.52) are shown with interpolated data between the soundings to highlight temporally consistent features (Fig. 11). The soundings ranged from approximately 150 to $700 \mathrm{~m}$ during this period. As mentioned previously, specific humidity tends to increase during the flight, particularly in the lower and middle levels. However, beyond JD 131.40 (9.6 UTC) there is actually a decrease in humidity in the lowermost levels, with maximum humidity in the sounding occurring at around $350 \mathrm{~m}$ altitude. Concurrent to this there is also a small increase in potential temperature at low altitudes. The wind speed and direction plots indicate relatively calm conditions, with greatest wind speed in the lower levels from a general southerly direction. In contrast, at the top of the soundings the balloon encountered winds from a northerly direction, above $600 \mathrm{~m}$. From JD 131.35 onwards, the observed winds became broadly southerly also at $600 \mathrm{~m}$. However, a band of rather more west-south-westerly winds developed at mid-altitudes $(\sim 450 \mathrm{~m})$, and low-level winds became (east)-south-easterly from JD 131.4 onwards. This indicates that the balloon was not strictly sampling a uniform air mass during this period. Whilst previous studies have used CMETs to study Lagrangian air mass trajectories (e.g. Voss et al., 2010), here the flight path is quasi-Lagrangian. As a consequence, the temperature and humidity trends observed along the flight path 

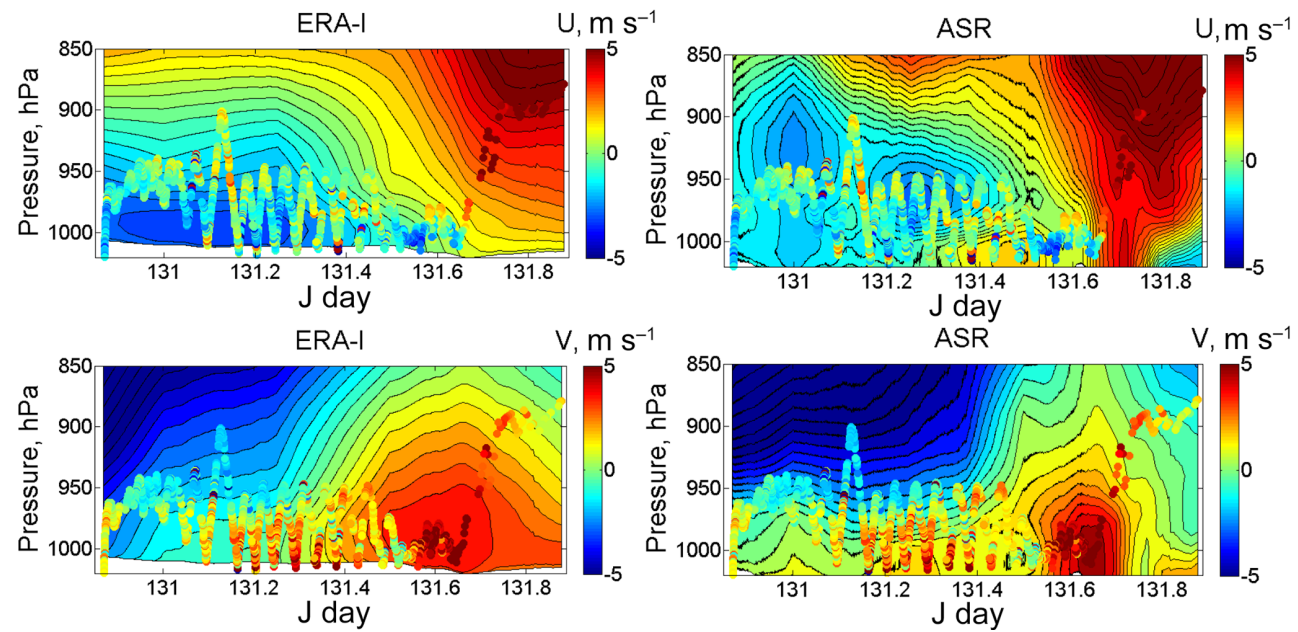

Figure 9. $U$ and $V$ winds observed during the CMET flight 5 soundings (filled circles) compared to 4-D interpolated (latitude, longitude, pressure, time) model data from ERA-I and ASR.

cannot be wholly interpreted in Lagrangian terms (e.g. tracing of diurnal signature on a single air parcel), rather they must also consider the Eularian perspective (e.g. advection of air masses with distinct properties into and out of the CMET flight path and their mixing).

The continuous series of CMET vertical profiles provide a more detailed overview of local-scale meteorology than is possible with traditional rawinsondes or constant-altitude free balloons. The CMET observations are consistent with the occurrence of a low-level flow that is decoupled from higher altitudes and - at least initially - an increase in surface humidity. The surface winds may be influenced by low-level channel flows. An outflow commonly exits from nearby Kongsfjorden-Kongsvegen valley (e.g. Esau and Repina, 2012) but is hard to identify from the ground station in Ny Ålesund (south side of Kongsfjorden) given the rather low wind speeds during this period. Winds that originate over land are likely to be colder, with lower humidity than marine air masses. Thus, the CMET observations of lower specific humidity between JD 131.40 and 131.5 (9.6-12 UTC) might be explained by fumigation from or simply sampling of such a channel outflow. Alternatively, the CMET location near Kapp Mitra Peninsula at this time may indicate an even more local source of dry air impacting low levels. A final possibility could be the overturning of air masses in the vertical, bringing less humid air with higher potential temperature to lower altitudes. At mid-levels $(\sim 450 \mathrm{~m})$ a relatively humid air layer persists, properties which suggest it has origins from the surface. It appears to be advected north-eastwards, potentially replenishing air over Svalbard to replace that which may be lost from the channel outflow.

Wind fields are estimated from the CMET balloon 5 flight path for an $8 \mathrm{~h}$ period starting in the early morning of 11 May (JD 131) (Fig. 12). As per previous figures, the CMET balloon movement during the soundings has been used to es- timate wind speed and direction. Here, wind trajectories are derived from the observed winds at $50 \mathrm{~m}$ altitude intervals for each up or down profile. The trajectory vectors (of length proportional to the wind speed $\times$ time elapsed between soundings) are placed end-to-end to estimate the wind field, shown in Fig. 12 (grey mesh), alongside the CMET flight (red). This approximate technique assumes horizontally uniform flow in the vicinity of the balloon and computed trajectories. The lowermost layer exhibited the greatest wind speed, thus has the longest (and least certain) trajectory, approximately double that of the balloon during the same period. The uppermost layer flows southwards before reversing direction, approximately returning to its initial position at $600 \mathrm{~m}$ altitude. The middle layer trajectory is quite similar to that of the overall CMET balloon flight, but is transported initially somewhat more westwards and later somewhat more eastwards, due to the ESE winds experienced in the late morning (see Fig. 11). It is worth noting that this final direction mirrors findings from two of the other CMET balloons, which have flight paths out of Kongsfjorden deviating to the north-east into the nearby Krossfjorden (Fig. 1). These balloon-based trajectories provide insight into the complex local dynamics of low-altitude circulation influenced by complex terrain. Furthermore, the trajectories and profile data can be computed and displayed in near-real time to inform the real-time in-flight decisions on CMET altitude control (e.g. to track specific layers or events of meteorological interest).

\subsection{Discussion: ASR and ERA-I model reanalyses in comparison to CMET}

Both reanalyses showed good general agreement with the CMET flights, finding more stable conditions for flight 4 (over sea ice) than flight 5 (coastal). For flight 4, ASR showed 

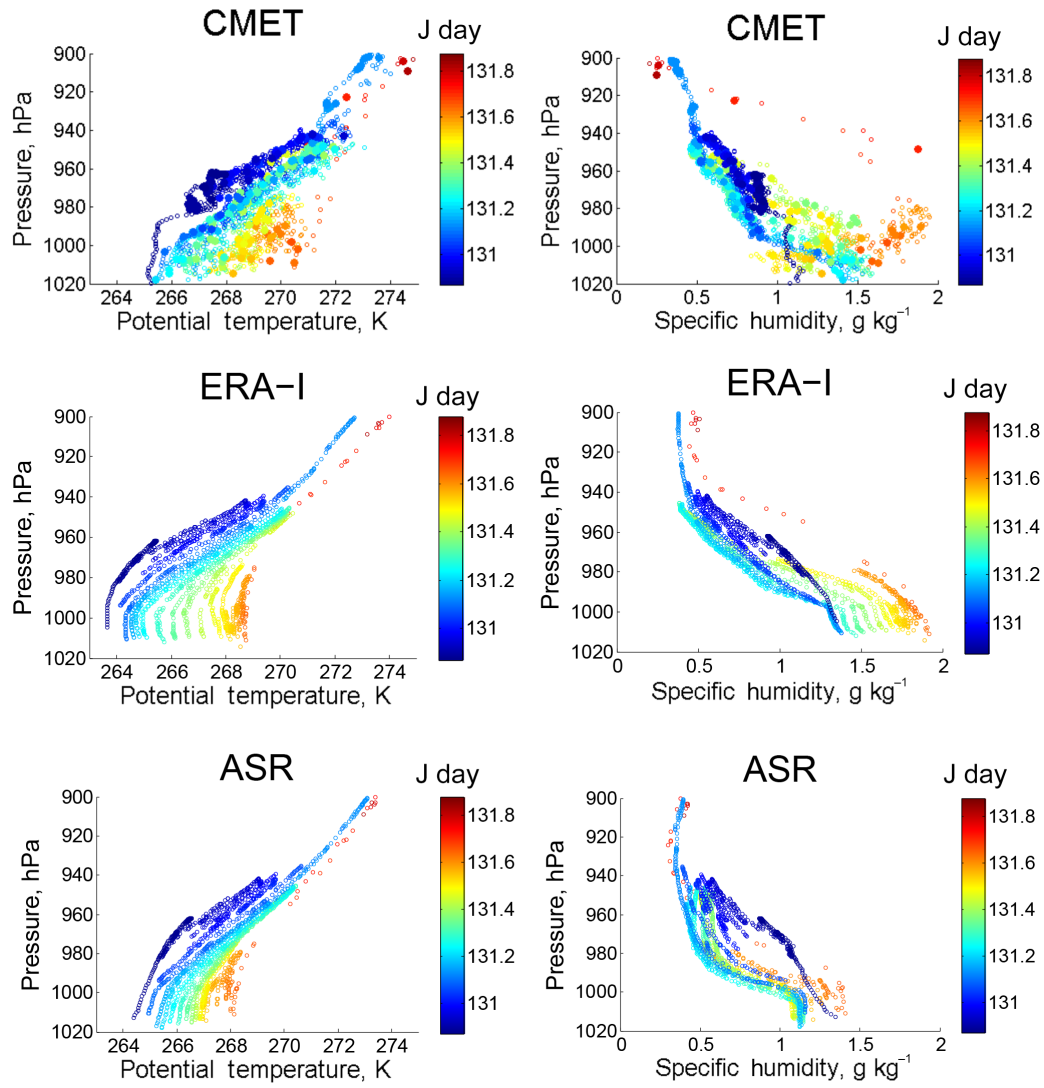

Figure 10. Profiles of potential temperature and specific humidity during flight 5 as observed by the CMET balloon and according to the 4-D interpolated ERA-I and ASR model outputs. CMET measurements made during descents only ( $>0.1 \mathrm{~m} \mathrm{~s}^{-1}$ vertical descent speed) are shown as filled circles and full data sets are shown as open circles.

a better capability than ERA-I to reproduce a temperature inversion observed over sea ice. ASR and ERA-I broadly reproduced the enhanced humidity near the sea ice surface but showed some discrepancies with the CMET in the verticalspatial distributions. For flight 5, ASR better reproduced observed wind shear near to the Svalbard coast. Both models exhibit increasing specific humidity and temperature in the near-surface atmosphere from morning to afternoon on JD 131, in agreement with the trend observed. However, compared to the CMET the surface temperature and humidity enhancements were underpredicted by ASR. ERA-I underestimated ABL temperature. Whilst increasing humidity and temperature over the daytime might be expected based on the diurnal cycle, Sect. 3.4 highlights the quasi-Lagrangian nature of flight 5 that also requires consideration of air mass advection and mixing. Figure 13 presents ERA-I (regionalscale) and ASR (local-scale) patterns for surface $2 \mathrm{~m}$ temperature and humidity for the duration of JD 131, alongside the CMET 5 flight path. A zone of warm and humid air initially to the south-west of Svalbard advects northwards and eastwards. This likely exerted a significant influence on the observed and modelled along-flight surface trends. The ASR also clearly shows local diurnal influences on surface me- teorology, particularly on $2 \mathrm{~m}$ temperature over the elevated topography east of the flight.

The temperature and humidity increases along flight 5 are temporally and spatially broader for ERA-I than for ASR (Fig. 8). This may to some degree reflect model diffusion on the larger ERA-I grid size ( $~ 80 \mathrm{~km}$ compared to $15 \mathrm{~km}$ for ASR). The poorer ERA-I resolution of Svalbard topography will also affect simulated meteorology in this coastal area, where there may be local mixing, e.g. between marineand land-influenced air masses. A major contributing factor to ASR performance in capturing observed wind shear (flight 5) and temperature inversion (flight 4) is likely the higher vertical model resolution of ASR compared to ERAI, with ASR having about double the number of model levels than ERA-I at $>800 \mathrm{hPa}$, see Methods for descriptions. This improves the representation of the shallow polar ABL with its distinct layers. Noting that higher-resolution models that better capture spatial patterns can nevertheless lead to worse agreement with observations due to slight spatial shifts (Wesselen et al., 2014), we choose not to reduce the ERA-I, ASR and CMET comparison to standard metrics (e.g. a correlation coefficient) here. The representations of Arctic air-sea-ice interaction and parameterization of turbulence fluxes in the 

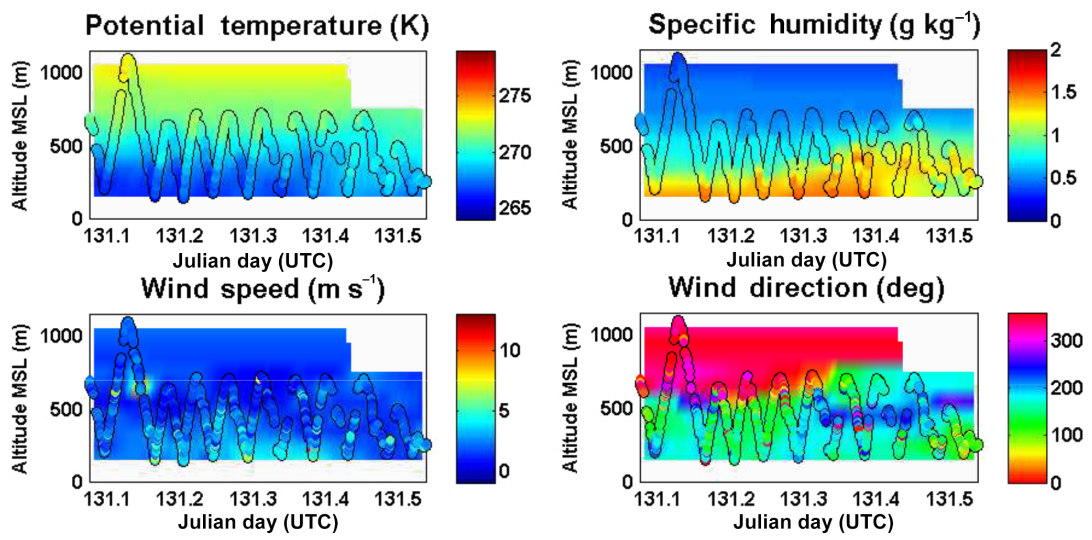

Figure 11. Potential temperature, specific humidity, wind speed and wind direction determined from the CMET balloon observations (131.08 to $131.52 \mathrm{JD}$, equivalent to $\sim 02$ to $12.5 \mathrm{UTC}$ on 11 May) of flight 5 during a series of automated soundings between 150 and $700 \mathrm{~m}$ altitude. Data between the balloon soundings has been interpolated.
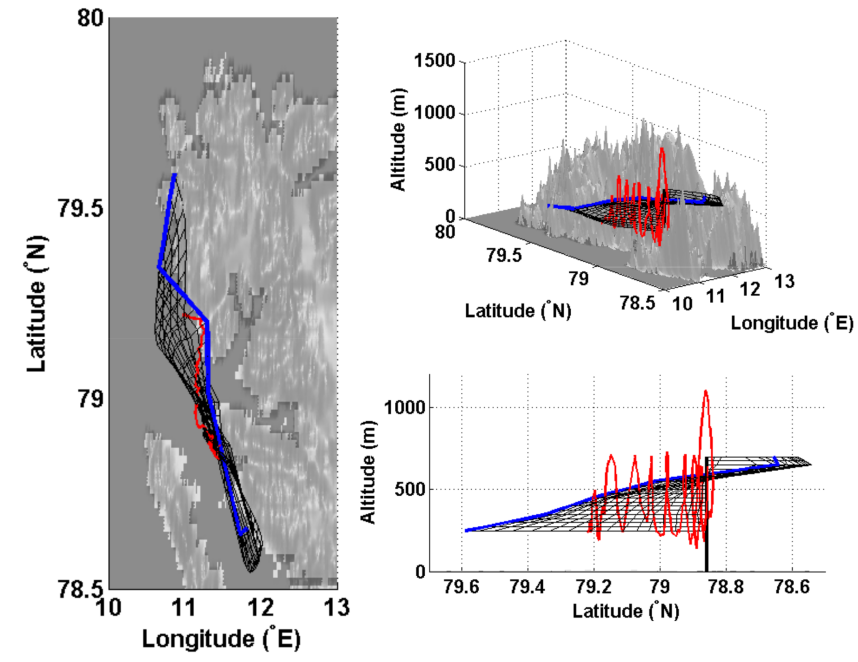

Figure 12. Wind field calculated from the CMET balloon flight 5. Air parcel trajectories are calculated over an $8 \mathrm{~h}$ period for each $50 \mathrm{~m}$ altitude layer according to the winds observed by the CMET soundings. The red line shows the actual balloon track, the black vertical line shows the initialization of the calculation and the derived air parcel trajectories (wind field grid) are shown in grey. The blue line shows the final locations after $8 \mathrm{~h}$.

boundary layer schemes will also influence the model outputs (e.g. Mölders and Kramm, 2010), but they are difficult to assess from this study. In future, this insight could be provided by campaigns in which multiple CMET balloons are sequentially colaunched to horizontally and vertically and probe an atmospheric region, combined with model sensitivity simulations.

\section{Conclusions}

Five Controlled Meteorological (CMET) balloons were launched from Ny-Ålesund, Svalbard on 5-12 May 2011, to measure in situ the meteorological conditions (humidity, temperature, winds, pressure) in the surrounding Arctic region. Repeated soundings were performed along the CMET flights that probed the Arctic atmospheric boundary layer. The CMET data are analysed in comparison to model output from the ERA-Interim and Arctic System Reanalyses.

CMETs are a novel balloon technology capable of multiday flights in the troposphere and performing in-flight soundings on command. Five CMET balloons were launched in May 2011. Balloons 1 and 2 had only short flights whilst balloon 3 made multi-day flights to the north but did not perform any soundings. Flights 4 and 5 made repeated soundings that profiled the ABL. CMET balloon 4 made two soundings of the boundary layer over sea ice to the east of Svalbard. Despite good performance this flight needed to be terminated to avoid encroaching on Russian territory. CMET balloon 5 was placed in an automated soundings mode and made a suite of 18 continuous soundings along the north-west coast of Svalbard, during a $24 \mathrm{~h}$ flight. To our knowledge, this was the first automated sounding sequence made by a free balloon.

This study focuses on the two flights that performed repeated profiling of the boundary layer. Overall both observations and models identify the ABL as more stable for flight 4 (over sea ice) than flight 5 (coastal). To the east of Svalbard (flight 4), the observed temperature and humidity increases towards the surface are generally well reproduced by ERA-I and ASR. The CMET observed a temperature inversion over sea ice which was reproduced by ASR but was not captured by ERA-I. ASR and ERA-I broadly reproduced the enhanced humidity near the sea ice surface but showed some discrepancies with the CMET in the vertical-spatial distributions. The CMET flight 5 along the north-west coast of Svalbard 

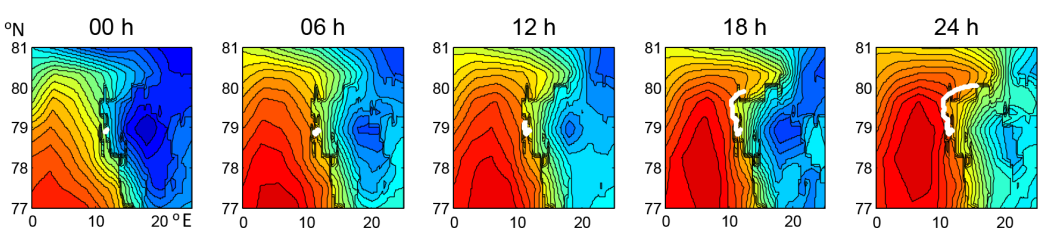

ERA-I

T $2 \mathrm{~m}, \mathrm{~K}$

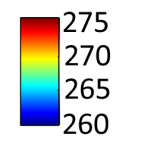

ERA-I
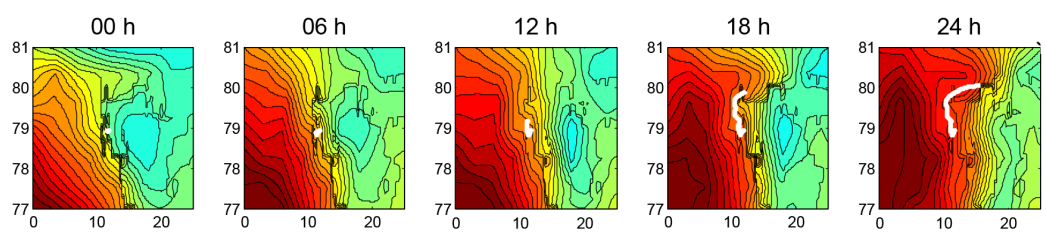

Q $2 \mathrm{~m}, \mathrm{~g} \mathrm{~kg}^{-1}$
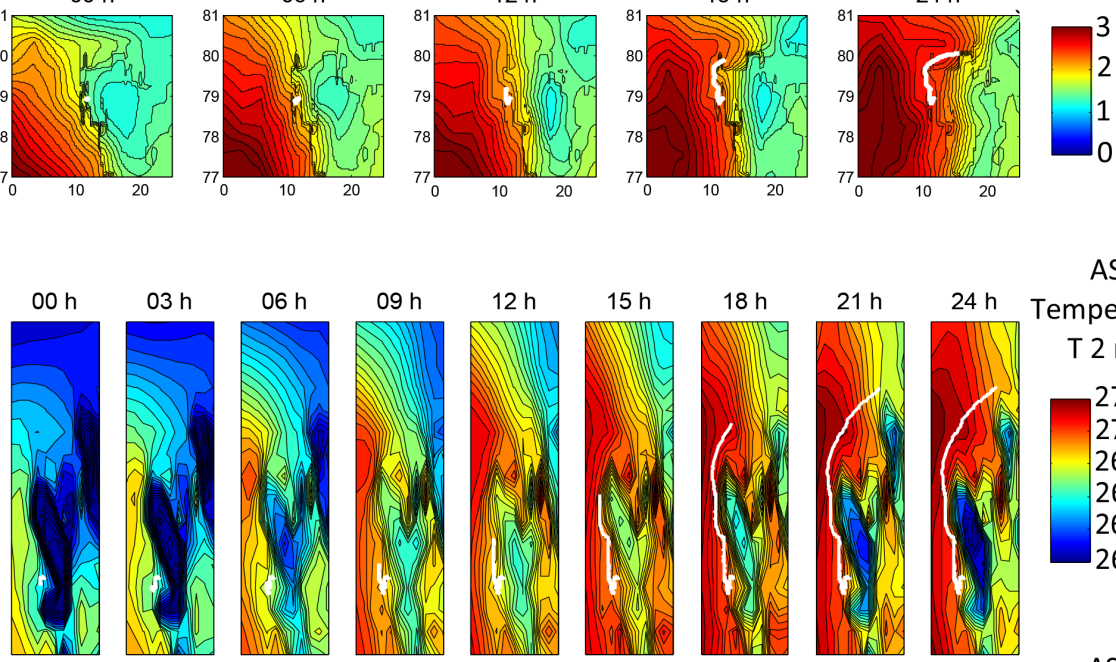

$\begin{array}{cc} & \text { ASR } \\ 24 \mathrm{~h} & \text { Temperature }\end{array}$
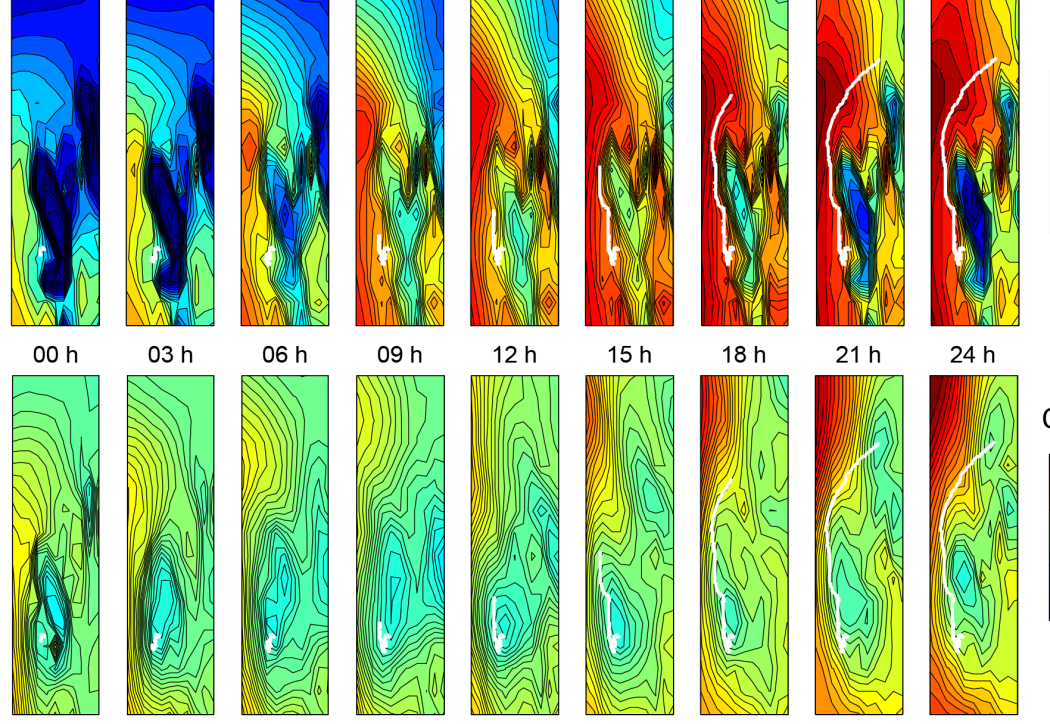

T $2 \mathrm{~m}, \mathrm{~K}$

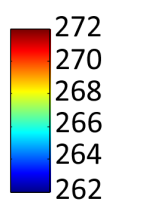

Figure 13. Surface $2 \mathrm{~m}$ temperature and specific humidity over JD 131 according to ERA-I (upper) and ASR (lower). ERA-I outputs are shown on the regional scale at 6-hourly intervals whilst ASR outputs are shown on a local scale at 3-hourly intervals. The CMET flight 5 trajectory up to each time point is illustrated as a white line.

observed increases in near-surface humidity and temperature and strong wind shear. Detailed analysis of the CMET data identifies a low-level flow and provides an estimate of local wind fields. The wind shear was captured by ASR but not ERA-I. Both model reanalyses find increasing surface specific humidity and temperature from morning to afternoon on JD 131. The enhancements are more spatio-temporally localized in ASR than ERA-I. The temperature enhancement was underpredicted by ASR whilst ERA-I exhibits a negative temperature bias on JD 131. The higher vertical and horizontal resolution of the ASR captures features (temperature inversion in flight 4, wind shear in flight 5) that are not described by ERA-I. However, there are other aspects of the model-observation comparison that are in better agreement for ERA-I than ASR. This might be due to the different rep- resentations of processes in the model and could be investigated in future by deploying a suite of CMET balloons over a region combined with model sensitivity studies.

In summary, CMET balloons provide a novel technological means to profile the remote Arctic over multi-day flights, including the capacity to perform continuous automated soundings into the atmospheric boundary layer. CMETs are thus highly complementary to other Arctic observational strategies including fixed station, free and tethered balloons, meteorological masts and RPAS/UAVs (drones). Whilst RPAS/UAVs offer full 3-D spatial control for obtaining the meteorological observations, their investigation zone is generally limited to tens of kilometres based on both range and regulatory restrictions. CMET flights provide a relatively low-cost approach to observing the boundary layer at greater 
distances from the launch site (e.g. tens to hundreds of kilometres), from tropospheric altitudes potentially all the way down to the surface, and more remotely from the disturbances of Svalbard topography. CMETs can provide new in situ data sets for for quasi-Lagrangian and long-range transport and process studies.

\section{Data availability}

The CMET balloon data analysed in this study can be visualized online at http://www.science.smith.edu/cmet/flight.html and accessed by contacting the CMET balloon principal investigator: Paul Voss at Smith College (pvoss@smith.edu). Two external model data sets were used in this work and are referenced in the text. ERA-Interim (ERA-I) model reanalysis data are available from http://apps.ecmwf.int/ (Dee et al., 2011). Arctic System Reanalysis (ASR) data v1 and soon v2 are available from http://rda.ucar.edu/ (Bromwich et al., 2016).

Acknowledgements. This research was sponsored by the Research Council of Norway and the Svalbard Science Forum. We are very grateful to the joint French-German Arctic Research Base AWIPEV in Ny-Ålesund for logistical support and Anniken C. Mentzoni for fieldwork assistance. Paul B. Voss also acknowledges Smith College for support. Tjarda J. Roberts acknowledges NSINK, an Arctic Field Grant, CRAICC, and the VOLTAIRE LABEX (VOLatils-Terre Atmosphère Interactions - Ressources et Environnement) ANR-10-LABX-100-01 (2011-20) for funding. This study occurred at the end of the Coordinated Investigation of the Climate-Cryosphere Interactions (CICCI) initiative. We are extremely grateful to the ASR team for providing model-level ASRv2 reanalysis data in advance of public distribution. We thank Chi-Fan Shih for help in accessing the ASR files and David Bromwich for useful comments on the manuscript.

Edited by: S. M. Noe

Reviewed by: three anonymous referees

\section{References}

Andreas, E. L., Guest, P. S, Persson, P. O. G., Fairall, C. W., Horst, T. W., Moritz, R. E., and Semmer, S. R.: Near-surface water vapor over polar sea ice is always near ice saturation, J. Geophys. Res.-Oceans, 107, C10, doi:10.1029/2000JC000411, 2002.

Bromwich D. H., Hines K. M., and Bai L.-S.: Development and testing of polar weather research and forecasting model: 2. Arctic Ocean, J. Geophys. Res., 114, D08122, doi:10.1029/2008JD010300, 2009.

Bromwich, D. H., Wilson, A. B., Bai, L., Moore, G. W. K., and Bauer, P.: A comparison of the regional Arctic System Reanalysis and the global ERA-Interim Reanalysis for the Arctic, Q. J. Roy. Meteor. Soc., 142, 644-658, doi:10.1002/qj.2527, 2016.

Dee, D. P., Uppala, S. M., Simmons, A. J., Berrisford, P., Poli, P., Kobayashi, S., Andrae, U., Balmaseda, M. A., Balsamo, G.,
Bauer, P., and Bechtold, P.: The ERA-Interim reanalysis: Configuration and performance of the data assimilation system, Q. J. Roy. Meteor. Soc., 137, 553-597, doi:10.1002/qj.828, 2011.

Esau, I. and Repina, I.: Wind Climate in Kongsfjorden, Svalbard, and Attribution of Leading Wind Driving Mechanisms through Turbulence-Resolving Simulations, Adv. Meteorol., 2012, 568454, doi:10.1155/2012/568454, 2012.

Hole L. R., Bello, A. P., Roberts, T. J., Voss, P. B., and Vihma, T.: Measurements by controlled meteorological balloons in coastal areas of Antarctica, Antarct. Sci., CJO2016, doi:10.1017/S0954102016000213, 2016.

Kilpeläinen, T., Vihma, T., and Olafsson, H.: Modelling of spatial variability and topographic effects over arctic fjords in svalbard, Tellus A, 63, 223-237, 2011.

Mäkiranta, E., Vihma, T., Sjöblom, A., and Tastula, E.-M.: Observations and modelling of the atmospheric boundary layer over sea-ice in a svalbard fjord, Bound.-Lay. Meteorol., 140, 105-123, 2011.

Maturilli, M., Herber, A., and König-Langlo, G.: Climatology and time series of surface meteorology in Ny-Ålesund, Svalbard, Earth Syst. Sci. Data, 5, 155-163, doi:10.5194/essd-5-155-2013, 2013.

Mayer, S., Sandvik, A., Jonassen, M., and Reuder, J.: Atmospheric profiling with the UAS SUMO: a new perspective for the evaluation of fine-scale atmospheric models, Meteorol. Atmos. Phys. 116, 15-26, 2012a.

Mayer, S., Jonassen, M., Sandvik, A., and Reuder, J.: Profiling the arctic stable boundary layer in Advent Valley, Svalbard: Measurements and simulations, Bound.-Lay. Meteorol., 143, 507526, 2012 b.

Mölders, N. and Kramm, G.: A case study on wintertime inversions in interior Alaska with WRF, Atmos. Res., 95, 314-332, 2010.

Moore, G. W. K., Renfrew, I. A., Harden, B. E., and Nernild, S. H.: The impact of resolution on the representation of southeast Greenland barrier winds and katabatic flows, Geophys. Res. Letts., 42, 3011-3018, doi:10.1002/2015GL063550, 2015.

Moore, G. W. K., Bromwich, D. H., Wilson, A. B., Renfrew, I., and Bai, L.: Arctic System Reanalysis improvements in topographically-forced winds near Greenland, Q. J. Roy. Meteor. Soc., 142, 2033-2045, doi:10.1002/qj.2798, 2016.

Persson, P. O. G., Fairall, C. W., Andreas, E. L., Guest, P. S., and Perovich, D. K.: Measurements near the atmospheric surface flux group tower at sheba: Near-surface conditions and surface energy budget, J. Geophys. Res., 107, 8045-8079, 2002.

Riddle, E. E., Voss, P. B., Stohl, A., Holcomb, D., Maczka, D., Washburn, K., and Talbot, R. W.: Trajectory model validation using newly developed altitude-controlled balloons during the international consortium for atmospheric research on transport and transformations 2004 campaign, J. Geophys. Res., 111, D23S57, doi:10.1029/2006JD007456, 2006.

Rinke, A., Dethloff, K., Cassano, J., Christensen, J., Curry, J., Du, P., Girard, E., Haugen, J.-E., Jacob, D., Jones, C., Kltzow, M., Laprise, R., Lynch, A., Pfeifer, S., Serreze, M., Shaw, M., Tjernstrm, M., Wyser, K., and Agar, M.: Evaluation of an ensemble of Arctic regional climate models: spatiotemporal fields during the sheba year, Clim. Dynam., 26, 459-472, 2006.

Smedsrud, L. H., Esau, I., Ingvaldsen, R. B., Eldevik, T., Haugan, P. M., Li, C., Lien, V. S., Olsen, A., Omar, A. M., Otterå, O. H., and Risebrobakken, B.: The role of the Barents 
Sea in the Arctic climate system, Rev. Geophys., 51, 415-449, doi:10.1002/rog.20017, 2013.

Stenmark, A., Hole, L. R., Voss, P., Reuder, J., and Jonassen, M. O.: The influence of nunataks on atmospheric boundary layer convection during summer in Dronning Maud Land, Antarctica, J. Geophys. Res. Atmos., 119, 6537-6548, doi:10.1002/2013JD021287, 2014.

Tjernström, M., Birch, C. E., Brooks, I. M., Shupe, M. D., Persson, P. O. G., Sedlar, J., Mauritsen, T., Leck, C., Paatero, J., Szczodrak, M., and Wheeler, C. R.: Meteorological conditions in the central Arctic summer during the Arctic Summer Cloud Ocean Study (ASCOS), Atmos. Chem. Phys., 12, 6863-6889, doi:10.5194/acp-12-6863-2012, 2012.

Vihma, T., Lüpkes, C., Hartmann, J., and Savijärvi, H.: Observations and modelling of cold-air advection over Arctic sea ice in winter, Bound.-Lay. Meteorol., 117, 275-300, 2005.

Vihma, T., Pirazzini, R., Fer, I., Renfrew, I. A., Sedlar, J., Tjernström, M., Lüpkes, C., Nygård, T., Notz, D., Weiss, J., Marsan, D., Cheng, B., Birnbaum, G., Gerland, S., Chechin, D., and Gascard, J. C.: Advances in understanding and parameterization of small-scale physical processes in the marine Arctic climate system: a review, Atmos. Chem. Phys., 14, 9403-9450, doi:10.5194/acp-14-9403-2014, 2014.
Voss, P. B., Zaveri, R. A., Flocke, F. M., Mao, H., Hartley, T. P., DeAmicis, P., Deonandan, I., Contreras-Jiménez, G., MartínezAntonio, O., Figueroa Estrada, M., Greenberg, D., Campos, T. L., Weinheimer, A. J., Knapp, D. J., Montzka, D. D., Crounse, J. D., Wennberg, P. O., Apel, E., Madronich, S., and de Foy, B.: Long-range pollution transport during the MILAGRO-2006 campaign: a case study of a major Mexico City outflow event using free-floating altitude-controlled balloons, Atmos. Chem. Phys., 10, 7137-7159, doi:10.5194/acp-10-7137-2010, 2010.

Voss, P. B., Hole, L. R., Helbling, E., and Roberts, T. J.. Continuous in-situ soundings in the Arctic boundary layer: A new atmospheric measurement technique using controlled meteorological balloons, J. Intell. Robotic Syst., 70, 609, doi:10.1007/s10846012-9758-6, 2012.

Wesslén, C., Tjernström, M., Bromwich, D. H., de Boer, G., Ekman, A. M. L., Bai, L.-S., and Wang, S.-H.: The Arctic summer atmosphere: an evaluation of reanalyses using ASCOS data, Atmos. Chem. Phys., 14, 2605-2624, doi:10.5194/acp-14-26052014, 2014. 